\title{
Milieu Relevance of Melanin's Antiviral Effects and Interventions to the COVID-19 Pandemic
}

\author{
T. Owens Moore ${ }^{1}$, Ph.D., Niyana K. Rasayon, MA ${ }^{2 *}$, Ph.D.
}

${ }^{\prime}$ Department of Psychology, Clark Atlanta University, Atlanta, GA 30314. United States.

$2^{2 *}$ Division of Social \& Behavioral Sciences, University of The District of Columbia, Washington, DC, 20008. United States.

\author{
Article Details \\ Article Type: Review Article \\ Received date: $15^{\text {th }}$ January, 2021 \\ Accepted date: $02^{\text {nd }}$ March, 2021 \\ Published date: $05^{\text {th }}$ March, 2021
}

"Corresponding Author: Niyana K. Rasayon, MA., Ph.D., Division of Social \& Behavioral Sciences, University of The District of Columbia, Washington, DC, 20008. United States. E-mail:niyana.rasayon@udc.edu

Citation: Moore, T.O. \& Rasayon, N.K. (2021). Milieu Relevance of Melanin's Antiviral Effects and Interventions to the COVID-19 Pandemic. J Ment Health Soc Behav 3(1):133. https://doi.org/10.33790/jmhsb1100133

Copyright: $\left({ }_{0} 2021\right.$, This is an open-access article distributed under the terms of the Creative Commons Attribution License 4.0, which permits unrestricted use, distribution, and reproduction in any medium, provided the original author and source are credited.

\begin{abstract}
The COVID-19 pandemic has disproportionately affected melanindominant people, while on the continent of Africa, this novel strain does not appear to have decimated the population. Contrary to many scientific expectations, native Africans on the continent are less impacted compared to the global number of infections in other regions of the world. Therefore, an analysis of the role of melanin and milieu should be assessed by healthcare providers who have a concern for melanin-dominant populations. Questions are raised that Melanin has antiviral effects and there are additional factors derived from comorbidity that impact the susceptibility to Severe Acute Respiratory Syndrome coronavirus 2 (SARS-CoV-2) embedded in institutional racism (aka the system of white supremacy-Milieu). Dietary practices, access to healthcare, lifestyle and genetics can influence the severity of illnesses associated with contracting this virulent coronavirus via intense erratic activation of the immune system among those subjected to a plethora of chronic societal stressors. In summary, this article will address the effects of this crisis on people of African descent and suggest alternative treatments as an intermediary, rather than exclusive reliance on a vaccine as preventative treatment. The relevance of such discourse is critical given America's medical history, which has fostered profound distrust among her melanin-dominant citizenry.
\end{abstract}

\section{Environmental Factors, Marginalization and Access to Intervention}

From historical evidence, one could speculate on whether this pandemic could have been conceived as a potential military tool, which would suggest that it was man made or a potential biological weapon [1]. Conversely, what we can accurately report on is the science behind how Severe Acute Respiratory Syndrome coronavirus 2 (SARS-CoV-2) effects manifest at a cellular level and degrades one's ability to maintain adequate delivery of oxygen throughout the body. SARS-CoV-2 is the novel virus identified as the cause of the current pandemic, aka the coronavirus disease 2019 (COVID-19). Upon inquiry several questions are raised. Does milieu, lifestyle and environment, the marginalization of resources and access to health care, all functions of structural racism morph into a critical link regarding Covid-19 diagnosis? Clearly, such factors merit scrutiny and detailed evaluations as evidenced by melanin-dominant people's vulnerability to this pandemic in densely populated areas with advanced technological resources. These variables were highlighted in interviews done by the BBC World News host Stephen John Sackur of HARD Talk. More importantly, they were confirmed by South Africa's Government Advisor Virologist Professor Barry Schoub. It is noteworthy that his position is comparable to the lauded position held by the USA's Chief Epidemiologist Anthony Fauci, who has again been appointed to lead a team of doctors, scientists, and public health professional to convince and deliver the "VACCINES" to the populace throughout the United States.

Global reports on the African continent, which is heavily concentrated with darkly pigmented people (melanin-dominant), indicates that the level of decimation seems to be less widespread, unless one is collecting data in regions of South Africa. In retrospect, early reports had taken the position that only elderly people were vulnerable [2], which was suggested to be exacerbated by proximity, immune system resilience and marginal mobility. Today we are acutely aware that the signature trail of COVID-19 is other than that. In fact, middle-aged as well as small children can contract the various illnesses associated with this novel coronavirus. Further, it appears that this Virus is an opportunistic virulent disease. However, there are some signature expressive characteristics that need to be better understood as we attempt to explore solutions for this swiftly spreading contagion. Whether manufactured or naturally occurring, this coronavirus has wreaked havoc on world populations, undermined how humans eulogize their loved ones across cultures, and destabilized economies. In this scientific analysis of the current literature and active researchers, we will explore the science behind why some people are more impacted by the severity of SARS-CoV-2. With interwoven themes intimately connected to melanin in science and health, as well as the profound yet summarily muted variable of one's milieu - Structural and Environmental racism. Unfortunately, beneath the rubric of comorbidity- the impact and the effects of this crisis on people of African descent (interchangeable with the term melanin dominant humans) is dismissed or nuanced under cumulative health problems, rather than definitive acknowledgment of institutional racism, euphemistic narratives embedded in socioeconomic disparities, comorbidity and marginalized access to health care are paraded before our eyes and ears in the media.

When considering over looked factors, there are some interesting connections between melanin [3], electronic technology [4], and the spraying of pollutants in the air [5] that can possibly affect the intensity of the infections. Also lacking in the media are reports on the specific mechanisms that are causing the illnesses associated with contracting SARS-CoV-2. Neither are we updated on findings in antivirals being developed. For example, Dr. Donald Alcendor, who is a Molecular Virologist and Associate Professor of Microbiology 
and Immunology at Meharry Medical College, currently proposed interventions for the COVID-19 pandemic. In fact, he asserts that, "When the virus gets inside the cell, the protein layer around the virus somewhat opens up and allows the virus to drift inside the cytoplasm," said Dr. Alcendor. "Our reagent will interact with the virus at that moment so that if you interact at a very early stage, there's no down stream viral proteins that are going to be made. So, it will shut replication down at the earliest stages and there are no viruses going to be made. We shut the virus down completely." Furthermore, we seldom hear reports about the effectiveness of treatments with agents such as interferon [6, 7]. Instead, we have an inundation of news stories about a potential vaccine for the entire world to be inoculated, while aware of the collective mistrust and ambivalence people of African descent harbor due to past preventative "protocols" and nefarious acts chronicled in history of medical experimentation on such populations. Harriet A. Washington the author of Medical Apartheid and Deadly Monopolies has produced comprehensive documentation which strongly suggest other treatments and perspectives may be merited rather than 'Godly Hope' tied to a vaccine.

It is quite clear that no one is immune from potentially contracting this virus. The reason is because everyone possesses the biological machinery that allows the virus to enter human cells. From the outset, viruses have neither legs to crawl nor wings to fly. There are ongoing scientific debates on whether viruses are alive [8], but we do know that viruses need to hijack your cellular components to replicate and survive. What COVID-19 has shown us is that viruses can easily survive if the contagion is in an airborne state, colloidal, aresolic or in distinct droplets, which has been agreed upon by virologists [9].

Too much of the daily discussion is on waiting for a vaccine that will be potentially useless against a virus that continues to mutate [10]. For people of African descent, emphasis should be placed on treatment, lifestyle change, and a biopsychosocial approach that can potentially diminish one's susceptibility to a threatening load of viral particles.

For example, there is a spike protein on SARS-CoV-2 that latches onto a specific protein receptor called angiotensin converting enzyme 2(ACE2). When the sticky virus and spike latch onto the ACE2 cell, it is like a burglar finding the key under the doormat. Since this coronavirus is so sticky and lethal, one might ask if it was purposely manipulated to target a specific biological system.

For people of African descent, there has been a history of exploitation on many levels $[11,12]$. When we refer to science experiments, there is a large body of research demonstrating how western medicine and "white" scientists have experimented on black populations worldwide [13, 14]. Therefore, it is easy to assume the mortality of the COVID-19 impact has been more severe in melanindominant communities in the United States. Some reports reveal 8 out of 10 COVID-19 related deaths reported in the US have occurred among adults 65 and older [15]. However, age is only one factor involved in the contraction of SARS-CoV-2. Although less studied, blood type might increase susceptibility and genetics may play a role as well. Some studies have shown, however, that $58 \%$ of the immune system is almost completely determined by nongenetic factors [15]. Therefore, it is lifestyle that becomes important to emphasize, as well as environment.

Among those who were hospitalized with COVID-19, 34\% had diabetes, $42 \%$ were obese and $57 \%$ had high blood pressure [15]. In black communities in the US, these health challenges plaguing the community can be attributed to lifestyle and access to healthcare. There is a hesitancy to say lifestyle choices because a person may not have a choice to shop anywhere else but a cheap dollar store. General Dollar, Dollar Tree and Family Dollar are places where diabetes, obesity and cardiovascular illnesses begin for many poor and low-income people. We are speaking of food deserts in which there are no healthy and live food establishments to choose from daily. Compound this with the lack of locations to exercise in a safe park and this increases the manifestation of illnesses.

Collectively, these environmental factors amplify the significant impact of milieu and structural/institutional racism combined with the daily grind and collective stressors of one trying to navigate a racist society.

\section{Global Dysregulation}

The structure of capitalism has grossly impacted health on a grand scale. The system of mass consumption, for example, has our physical bodies out of order, and it has caused our bodies to manifest many unwanted immune problems. Chronic inflammation, autoimmune diseases, and food allergies stem from an excessive consumptionoriented society that is abound with stressful life experiences. Detrimental levels of cortisol are a typical hormonal response to one's efforts to navigate systemic racism.

Chronic inflammation are common manifestations associated with a range of diseases from diabetes, high blood pressure and obesity. Even a neurodegenerative disease like Alzheimer's disease and similar forms of dementiaa reviewed as chronic inflammatory disorders. In relation to COVID-19, when a viral infection happens during chronic inflammation, the immune system may either not be able to mount an appropriate response or it tries to overcome it leading to a "cytokine storm." The storm is a massive influx of immunoresponsive chemicals that are trying to re-establish balance in the body.

The American diet and the mass consumption of processed foods can set the body up for failure. High fructose corn syrup and sugary foods can attribute to diabetes. High salt content in fried foods contribute to hypertension and a host of other cardiovascular issues. The combination of these poor dietary choices and a sedentary lifestyle contributes to the high incidence of obesity. Capitalistic systems are typically wedded to selective material gain or greed, rather than concerns about a healthy citizenry. The priority is to make money. As people are trying to make money, their lives become more stressed while trying to accumulate quantifiable wealth. With the high stress of social conditions, the body can become dysregulated and begin to fight itself. In fact, there are nearly 80 distinct autoimmune diseases, all of which seem to share the common underlying issue of the body's immune system attacking itself [16]. Moreover, autoimmune diseases can attack joints, glands, the digestive system, and the nervous system. Invariably, combined degradation of the human body functioning as a system undermine healthy cognitive functioning.

During the hustle of life and the monotonous routines, the stressful life experiences can cause cells to attack each other. Subsequently, an overtaxed, weakened, or dysregulated immune system can allow SARS-CoV-2 to wreak havoc throughout the entire body.

In this capitalistic society, processed foods and mass marketing are the key modes of operation and profit. The addition of artificial substances in foods and the rates of allergies from items such as nuts, milk or shellfish can trigger the immune system to overfire [15]. As a result, one is more vulnerable to compromises in their health.

Over years of capitalistic development, our bodies have been exposed to thousands of chemicals like heavy metals, industrial pollutants, and pesticides. In some cases, the chemicals can be immune activating and cause inflammation or immunosuppressive and make the body susceptible to attack [7].

Overall, this global dysregulation is not only affecting citizens of the United States, but populations throughout the world who are trying to emulate the American way of living are now experiencing many physical abnormalities linked to a poor diet and lifestyle. 
For melanin-dominant people living in a capitalistic society, SARSCoV-2 is greatly impacting overall health. A general decrease in physical exercise, ever increasing levels of microaggressions, continual stress and advancing age are factors that have laid siege to our immune system like never before [17].

The COVID-19 pandemic has shown we are not immune to anything; actually, we are susceptible to everything and what we must do is build a defense mechanism system and maintain a context for discussions about vaccines for mass immunization. It is no secret that a number of melanin dominant people have profound reservations, regardless of the reported efficacy. By living in a capitalistic system, you are forced to defend yourself every day against the onslaught of overt and covert acts that make it unusually difficult to make a decent living. The cumulative impact of these attacks which occur in many forms, demand reasonable access to information and resources for greater preparedness to thrive and survive.

It is a matter of fact that any science reported in this article could change in a matter of weeks. The novel coronavirus has World Health agencies (i.e., WHO) and reputable science agencies (i.e., CDC) confused and changing the story on a weekly basis on how to respond to the pandemic. One could easily surmise, based on "scientific commentaries" that experts are practicing on people and the lives of innocent people are profoundly compromised or sacrificed when poorly researched health advice is continually given.

\section{Entry Point}

Like most colds and viruses, the transmission is airborne. The point of entry into the body could be by the mouth, eyes, and nose. Therefore, in those places of moisture is where the virus can lurk and attack the entire body in a stealth like manner. The skin, the hair and ears are other points of entry into the body, but there is no evidence that SARS-CoV-2 enters through these non-moist areas. Yet, viral particles can remain viable until naively being transferred to a moist area later
Melanin is at the core of this discussion when comparing the effects of pathogens on ethnicities. Different ethnic groups, for example, display different levels of the pigment on the external layer of the body. Genetically speaking, the amount of melanin on the outside of the body impacts the overall function of melanin internally [18].

As a complex biopolymer, melanin can serve as a double-edged sword. On the positive side, it protects cells from foreign agents to keep the body fit. On the negative side, melanin can absorb and collect toxic material, and this can eventually lead to cellular damage. Having melanin, however, is a needed sword to fight against a multitude of illnesses, so the presence of melanin is a biological advantage [19].

You can have total control over your body as a vessel for life and good health by understanding what is going into your body. For example, this lacks practicality for most people, however, it is worth mentioning. If you grew your own food, there would be no need to read the label on items. The capitalistic society we live in manipulates access to what we consume. Many items that are processed for your consumption are easily made available and marketed, even when science clarifies how you could be adversely impacted. When you are eating manufactured items, you have lost control over your life. You can have some semblance of control by at least reading what is on the label, that is, assuming the jargon does not require a degree in chemistry. With so many chemicals, it is difficult to call it food. People are sicker today and unhealthier than the past because of the numerous chemical concoctions that are masquerading as food. The body is under constant attack from all these chemicals and the longterm effect is a weakened defense system. When you get sick, you do not want to wait for medical treatment that may never come. Taking control of your health is the first defense to maintain a healthy system. Table 1 demonstrates food items that can support the immune system, particularly in today's climate. [Insert Table 1 here].

\begin{tabular}{|c|c|}
\hline Vegetables & [Kale, broccoli, brussels sprouts, collard greens, cauliflower, and cabbage] \\
\hline Fruits & $\begin{array}{l}\text { [Watermelon, strawberries, peaches, and citrus fruits (oranges, grapefruits, lemons, limes, } \\
\text { kiwi, and cantaloupe)] }\end{array}$ \\
\hline Quinoa & $\begin{array}{l}\text { (A gluten-free seed that offers a healthy balance of essential amino acids, and is a good source } \\
\text { of protein for vegan and vegetarians) }\end{array}$ \\
\hline $\begin{array}{l}\text { White button } \\
\text { mushroom }\end{array}$ & (A friendly source of vitamin D2) \\
\hline Honey & $\begin{array}{l}\text { (Used as a natural sweetener that can have anti-bacterial properties and the ability to hinder } \\
\text { cancer cell proliferation) }\end{array}$ \\
\hline \multicolumn{2}{|c|}{$\begin{array}{l}\text { Adapted from Moore, J.G. and Chilcoat, A. (2020). Purple Mind: Shield of Protection. Institute of Medical } \\
\text { Imaging Procedures. }\end{array}$} \\
\hline
\end{tabular}

Since ACE2 receptors are the major entry site into biological cells, we need to understand the diabolical nature of this coronavirus and how it wreaks havoc on multiple systems. The ACE2 receptor is a hook for the spike protein on SARS-CoV-2. The receptor or hook is found throughout the body to affect respiration, blood pressure and cardiovascular integrity. The nose appears to be a sufficient reservoir because the olfactory cells lining the upper part of the nose contain up to 700 times more ACE2 receptors than cells lining the rest of the nose and windpipe that leads to the lungs [20].
In addition to ACE2 receptors, TMPRSS2 receptors are good hooks for coronaviruses [20]. Both receptors are found in the eyes, intestines, and noses of humans. By looking at the range of symptoms and related illnesses linked to SARS-CoV-2 (See Table 2) [Insert Table 2 here], it is the presence of these receptors in these various body regions that can explain the reason for the wide range of illnesses.

\begin{tabular}{|l|l|}
\hline Fever & Muscle Pain \\
\hline Lethargy & Cough \\
\hline Sore throat & Shortness of breath \\
\hline Diarrhea & Loss of smell/taste \\
\hline \multicolumn{2}{|c|}{ Table 2.Illnesses linked to SARS-CoV-2 Infections } \\
\hline
\end{tabular}




\section{ACE2 Hardware}

All over the body there exist ACE2 receptors in pigmented areas that are moist with a connection to blood, oxygen, and air flow. The ACE2 receptor hardware is important to understand how the body is constructed to keep a healthy state. Moreover, the antiviral and antioxidant properties of melanin are found in these moist passage ways to prevent or sequester the entry of harmful substances. Therefore, melanated areas of the body can be attractive locations for viral agents to attach and cause a host of physical ailments.

Along with these moist areas, the constant flow of blood through the body must be maintained and regulated. When people experience hyper- or hypotension, these effects can have devastating bodily consequences. Of the many factors controlling blood flow, ACE2 becomes critical to understand in the context of the COVID-19 pandemic. When one speaks of "blood pressure," it is the arterial pressure that is usually referred to versus venous pressure. All our organ systems require blood flow and these intricate mechanisms associated with blood pressure are adversely impacted by SARS-CoV-2 .

The kidneys, for example, have receptors that react to the changes in blood pressure. As darkly pigmented organs, the kidneys are especially important to help filter the body from toxins entering from the blood. Kidney failure can result when there is a lack of water for a long period of time. During dehydration as well as the exertion of physical activity, blood pressure is increased to maintain the right electrolyte balance, and it starts with the kidney filtration system.

Acids, bases, and salts are known as electrolytes because when in water solution, they conduct an electric current. Melanin is a natural semi-conductor, so it is able to add charge to the body and act like a battery. Therefore, pigmented cells containing melanin can be highly reactive to various elements with a charge. Water, electrolytes, and melanin can be considered the basic elements of life and the body has developed sophisticated mechanisms to ensure the sustenance of the human body on a chemical level. Reduction of blood flow through the kidney, for example, sends messages to the brain to release an antidiuretic hormone (i.e., vasopressin) to constrict blood vessels to conserve fluid. In this process, the kidneys release the enzyme called renin because the afferent arterioles respond to pressure changes. This generalized constriction of the arterioles causes a compensatory increase in arterial pressure [21].

The force of the heartbeat changes to affect multiple organ systems, and the increased blood pressure overcomes the effects of the vasoconstriction. This is all controlled by chemical factors that can be disrupted by SARS-CoV-2. Hypertension has a detrimental effect on the heart because the increased peripheral resistance is a force against which the heart must forcefully contract. Blood pressure is raised above normal when the distensibility of the arteries is reduced. High pressure causes vessels in the head and brain to be overfilled with blood, and impairment of brain function may occur. On the other hand, hypotension is when the pressure is below normal, and if untreated it results in damage to the heart and kidney and increases the likelihood of strokes. All of which the collective body of medical literature affirms to be related to systemic racism and poor dietary practices which are fueled by structural and environmental racism.

From the kidneys, the enzyme renin converts angiotensin I into angiotensin II. Beyond the brain, renin in the blood activates the plasma globulin known as angiotensinogen to form angiotensin I [22]. Under the influence of another plasma enzyme, the two amino acid units are split off from angiotensin I to form angiotensin II. Angiotensin II is a very potent vasoconstrictor, and it raises blood pressure. Therefore, an effective pharmacological treatment for blood pressure can be ACE2 inhibitors (e.g., Captopril and Lisinopril) for some people. Given the nature of the discussion in this article, the use of ACE2 inhibitors to treat blood pressure can make the body more susceptible to SARS-CoV-2. One does not need to do another study or comb the literature to clarify who are the people disproportionately diagnosed with hypertension.
Calcium channel blockers like Amlodipine, however, may be effective, and monotherapy with diuretics have been prescribed for some high blood pressure patients. Many people are given "water pills" or diuretics to treat high blood pressure. The diuretics prescribed are most likely thiazide diuretics to reduce blood pressure and Chlorthalidone which is a type of water pill. From a neuroendocrine perspective, the body's natural antidiuretic hormone is known as vasopressin. Vasopressin is a neuropeptide that helps the body to conserve water and the resultant effect is a raising of blood pressure. Therefore, water pills are counteracting a natural mechanism that has evolved since the existence of humanity to keep us properly hydrated. In the process of excessive urination from water pills, these diuretics help rid the body of salt and water and this can relieve high blood pressure.

Angiotensin II also helps trigger thirst, and when angiotensin II reaches the brain, it stimulates neurons in the areas adjoining the third ventricle called the circumventricular organs. Those neurons send axons to the hypothalamus, where they release angiotensin II as their neurotransmitter [23].

Angiotensin II stimulates the release of aldosterone from the adrenal cortex. In humans, aldosterone is the only physiologically important mineralocorticoid, and mineralocorticoids play an important part in regulating electrolyte metabolism [24]. Its primary function seems to be to maintain homeostasis of blood sodium concentrations. For example, aldosterone stimulates renal cells to increase their reabsorption of sodium ions from tubule urine back into blood. Because of its primary sodium re-absorbing effect on kidney tubules, aldosterone tends to produce sodium and water retention but potassium and hydrogen ion loss.

In sum, angiotensin II stimulates the zona glomerulosa of the adrenal cortex to increase its secretion of aldosterone. It has been noted that the pineal gland can secrete a hormone that stimulates aldosterone secretion, and this makes sense because the pineal gland is located next to and near the circumventricular organs in the third ventricle. Any alteration in this processing of sodium levels can influence energy levels. Therefore, the lethargy associated with contracting SARS is a very real experience. The mental fog in the normal flu-like tiredness is due to disrupted homeostasis.

Aldosterone is a steroid-shaped compound that looks like the stress hormone, cortisol. Cortisol is a glucocorticoid, and there has been an over reliance on glucocorticoids as anti-inflammatory agents. The challenge now is to develop anti-inflammatory drugs with equal efficacy to glucocorticoids without the associated side effects $[7,25]$ to treat COVID-19 symptoms.

The brain and the immune system express many neuropeptides and cytokines in common, and this has led to the proposition that immuno neuropeptides may be involved in the etiology of, or response to, processes which lead to immunological dysfunction [25]. The critical role played by immuno neuropeptides is the modulation of cytokine secretion from the lymphocytes in response to glucocorticoids and catecholamines released into the blood during inflammation or stress. Since activated T cells and B cell lymphocytes can express neuropeptides associated with stress reactions and pain relief, research into this sophisticated system for the control of inflammatory processes is essential for the development of specific and selective therapeutic compounds which can be directly targeted to the site of the inflammation. Characterization of the cytokine profile released by lymphocytes in response to hypothalamic-pituitary-adrenal axis (HPA) and sympathetic medullary system (SMS) activation may provide insight into why so many inflammatory autoimmune diseases are exacerbated by stress [25]. This begs the issue of clarity and simplicity to help better understand the signature "cytokine storms" associated with this virus.

\section{Melanin Reservoir}

It is very disturbing how there is no clear discussion on the proper use of blood pressure medicines, diet alterations, or ethno-specific 
treatments that could be managed. Table 3 [Insert Table 3 here], for example, represents nutrients and herbs to support a healthy immune system. Instead, all we hear is the vaccine is our panacea of protection. For dark skin melanin-dominant people of African descent, it is imperative to take full responsibility for knowing that Western medicine has irrefutable history of not placing the health of nonwhite people as a priority. Even if someone was compelled to debate the issue, there is no denying the health disparities we see on a global level.
Discrimination has created major problems in human relations and only serious and honest discussions can rectify the health disparities. When you conceptualize that "black" or "dark" is bad and that melanin is a "waste product," science will never understand the mechanisms in which melanin can promote life. For example, any healing or repair of tissue that occurs in a living organism (i.e., fruit, animal, or human body) turns brown or dark during the healing or repair. This is melanin in action to help prevent further damage to the tissue and to promote healing [26].

\begin{tabular}{|l|l|}
\hline Folic Acid & Vitamin E with Selenium \\
\hline COENZYME Q10 & Vitamin C \\
\hline Zinc & Vitamin D \\
\hline Astragalus & Quercetin \\
\hline Probiotics & Flax Seed Oil with Lignans \\
\hline $\begin{array}{l}\text { Herbs (Capsicum fruit, burdock root, goldenseal root, parsley herb, horehound herb, althea root, bitter } \\
\text { orange fruit and yerba santa herb) }\end{array}$ \\
\hline $\begin{array}{l}\text { Mushroom Blend containing six organic mushrooms (Reishi, Turkey tail, Chaga, Shiitake, Agaricus/ } \\
\text { white button, and Cordyceps) }\end{array}$ \\
\hline $\begin{array}{l}\text { Adapted from Moore, J.G. and Chilcoat, A. (2020). Purple Mind: Shield of Protection. Institute of } \\
\text { Medical Imaging Procedures. }\end{array}$ \\
\hline
\end{tabular}

In a related discussion on ethno-specific illnesses, coccidioidomycosis is one of the most infectious of the fungal diseases, and it is endemic in the desert valleys of California and the dry dusty areas of southwestern United States especially in Arizona, New Mexico, Texas, and part of Mexico [6]. It is most likely that man and animals are infected by the inhalation of spore bearing dust. This scenario is no different than the zoonotic diseases like the association of bats spreading coronaviruses to humans. Melanin may serve as a reservoir for this coccidioidomycosis infection to take hold. The pulmonary symptoms may vary in severity, but we have known for decades that it differentially impacts ethnic groups. Sometimes there is a cavitation in the lungs, and patients can recover. As a rule, the infection ends in recovery, but in a small percentage of cases the process spreads from the lungs to produce the progressive form which can spread [6]. If it is known that this occurs more frequently in melanindominant populations, we cannot be naïve to think studies could not be performed in a lab to concoct illnesses that darkly pigmented ethnic groups could be more prone to sickness $[1,3,5]$. Beyond the skin and the bones, it is interesting that this airborne fungal pathogen can spread like coronaviruses to subcutaneous tissues, meninges, and internal organs. Melanin is a reservoir in these body parts where these pathogens can accumulate.

Melanin is visible on the external portion of the body, and it is strategically located internally. Melanocytes are melanin producing cells originating from the neural crest. This is critical to knowing the origin because the melanocyte stem cells migrate from the neural crest to the skin and to mucous membranes. Note, the ACE2 receptors are found abundantly in moist areas of the body. The active melanocyte migrates to the stria vascularis of the cochlea, the leptomeninges, in the substantial nigra and locus coeruleus of the brain, the heart, and the optic cup of the retina [27]. Comparing these body sites with the manifestation of the illnesses in Table 2 demonstrates a link between ACE2, melanin and how viral agents affect the body. Western science will still report no significant biological role for melanin in these internal sites because this is the continual downplay of the power of pigmented cells, which is consistent with marginalizing the role and relevance of such people in science and history.

Even if one decides to ignore the essential role for internal melanin, one cannot deny its antiviral impact and a location which ACE2 receptors are found in combination with darkly pigmented cells. J Ment Health Soc Behav

Volume 3. 2021. 133
Beyond the nose, oral melanocytes and physiological oral pigmentation are genetically determined [27].

SARS-CoV-2 easily enters the mouth and nose region and that is why masks have been critical in the fight against the spread of the contagion. With melanin near these entry areas in combination with ACE2 receptors, it becomes a lethal combination for entry. Once in the body, the virus can wreak havoc on other systems where the receptors are heavily saturated. As a result of this saturation, respiratory, cardiovascular, and neurological illnesses persist.

On the topic of pigmentation, it is worthwhile to note the side effect from a controversial treatment that was touted as an effective treatment for COVID-19, hydroxychloroquine (HCQ). Initially, HCQ was first developed as an anti-malarial agent. It has anti-inflammatory and immune modulating properties [28]. It is toxic and it has been proven to be controversial in its effectiveness to treat COVID-19. However, HCQ-induced hyperpigmentation of the skin is a side effect from this therapy. Typically, HCQ-induced hyperpigmentation presents a blueish, blue-grey macules/patches most commonly on the shins, but can also be seen along the arms, forearms, face, oral mucosa, trunk, nails, and axilla [29]. The hyperpigmentation has nothing to do with the sun, so there are some biological mechanisms associated with melanin and HCQ treatment that are poorly understood.

Therefore, we cannot overlook the genetic connection related to viral susceptibility and melanin production. Since HCQ-induced hyperpigmentation is more common in dark skinned individuals likely due to greater melanin levels in dark skin, we can associate the greater risk of disease in melanin-dominant systems. It is not a simple matter to say Black people in the USA are disadvantaged with poor health choices. A combination of factors involved, so let us look at melanin-dominant people on the African continent.

\section{The African Continent}

It would be obvious to say melanin-dominant people in Africa are less impacted by COVID-19 mortality because of melanin, but we must analyze other factors. Many of the early transmissions in Africa have been from melanin-recessive travelers returning to Africa from overseas. For example, white South Africans traveling from Europe and going to South Africa triggered the spread in the southern region. Chinese foreigners helping to construct buildings and railways in Kenya or visiting eastern ports of Africa could have attributed to the spread of COVID-19 cases in Africa. 
Since there is less travel for many native Africans leaving and returning to their countries, the spread was not as devastating compared to other countries like Brazil and India, which incidentally are typically more densely populated.

Scientists are baffled as to why COVID-19 has not decimated countries in Africa. Two very intriguing differences, and potentially impacting are the use of $5 \mathrm{G}$ towers and the release of chemicals from military planes that are not as prevalent in many regions of Africa. Therefore, the underdeveloped portions of Africa that are not exposed to $5 \mathrm{G}$ technology or the spraying of chemicals conceivably have lessened the impact and spread of the airborne SARS-CoV-2. Conjecture on the science revealing how viruses exist in the atmosphere and how chemical biological warfare programs have sprayed harmful agents to kill off populations is documented $[1,5,14]$. Such scenarios are plausible given the long-term goals of a sustainable planet and themes embedded in the Global 2000 Report. In addition, the connection with $5 \mathrm{G}$ technology relates to the frequencies emitted from the electromagnetic radiation that could trigger cells to be targeted for easy entry [4]. Viruses are like crystals and we know certain frequencies of sound can crack glass. We can surmise the lack of technology in many regions of Africa has limited the harmful impact of $5 \mathrm{G}$ electromagnetic radiation on human physiology in this part of the world.

Also, the vitamin D story is a factor to consider because one would not expect low levels of vitamin D in Black Africans. In contrast, Black Africans living in America have noticeably lower levels of vitamin $\mathrm{D}$ to make the assumption that low vitamin $\mathrm{D}$ may attribute to COVID-19 susceptibility [30]. To highlight this relationship to melanin, Vigneri reports that researchers at the Trinity College in Dublin analyzed data from studies in Europe. Interestingly, the populations of northern countries like Finland and Sweden have higher levels of vitamin D than southern European areas like Spain and Italy. The northern region has a lower rate of coronavirus infection mortality.

Time will reveal the impact of COVID-19 on the African continent, and the mortality rate could change in months after this article is published. Either way melanin helps to fight disease and African people on the continent of Africa are not eating the low-quality diets seen in the USA. And, to reiterate, "Blacks" in America reportedly $82 \%$ have low levels of vitamin D. [31]. More quality food that is natural is better for the body. Access to quality water may be problematic in rural areas, but overall, the airborne nature of this coronavirus seems to be not as lethal on the continent of Africa.

\section{Steroid Hormones}

A critical treatment that must be delicately managed is the use of steroids. The physical appearance and presence of steroids in the human body are valuable for life. As concluded in the last section and the connection to vitamin $\mathrm{D}$, vitamin $\mathrm{D}$ is a steroid hormone. The sun is a necessity for life, and the steroid produced in the skin from the sun helps boost the immune system and protect bone density. Studies have shown that the lower a population's vitamin D levels, the higher the number of COVID-19 infections and the greater its rate of mortality [32]. Since vitamin D can help regulate inflammation and reduce the risk of cytokine storms, it can lower COVID-19 deaths.

The cytokine storms that form the internal regulation of steroids have been under intense investigation, and the topic is complex in relation to melanin. Melanin could be viewed as a biopolymer, neurotransmitter, or hormone. We know it is protective, so it can protect life in various roles. Although the most common effect is as a protective sunscreen from ultraviolet radiation, melanin physiology is much more detailed and pertinent with respect to one's collective health and physiological resilience, particularly its relationship with sunlight and vitamin-D synthesis.

Cytokines are proteins released by cells to send messages to other cells that a viral invasion is underway. Steroids, which dampen the entire immune system, are prone to altering one's cellular environment to become more vulnerable to other infections. As a result, many COVID-19 patients may be dying from their immune response to the virus and not from the virus, rather diffuse inflammatory responses throughout the body. The immune system's hyper responsivity can be severe enough to exacerbate a chain reaction of varying degrees of inflammation in the lungs, thereby diminishing oxygen turnover in the alveoli causing loss of ability to expand and constrict to expel carbon dioxide, which inevitably fosters fluid build- up, pneumonia, and over time prolonged stress leads to organ failure due to inadequate oxygen saturation.

Typically, during the cytokine storm, interferon is produced by $\mathrm{T}$ cells and natural killer cells. The antiviral properties of interferongamma display powerful anti-proliferative and immunomodulatory activities. A 3-dimensional image of interferon-gamma reveals a crystalline structure [6]. We know viruses have crystalline structures, so external frequencies could have a significant impact on the neuroimmunoendocrinology interactions to make a person well or sick; it depends on the vibratory state of the specific frequency and/ or erratic electromagnetic pulses.

Altering the immune response is a tricky proposition. It posits that the best way to help some patients survive COVID-19 may not be to fortify the immune system so that it can fight the virus with greater ferocity, but to subtly suppress the counterattack, so that the patient avoids self- destruction. The notion is controversial, not least because differentiating inappropriate immune response from a selfharming one can be difficult. An added wrinkle is the fact that SARSCoV-2, the virus that causes COVID-19, may itself stifle aspects of the immune response, meaning that additional immune suppression could make things progressively worse.

\section{Melanin and Melanocytes}

When we add melanin to the topic, melanins have the capacity to sequester metal ions and to bind certain drugs and organic molecules [19]. Melanin possesses both antioxidant and reactive oxygen species-dependent cytotoxic properties. SARS-CoV-2 presents as a very receptive cluster of viral material for melanin to attract and absorb.

Melanin itself can neutralize bacteria derived enzymes and toxins, and since it has strong binding properties, it can also act as a physical barrier against microorganisms. Melanocytes can act as antigen presenting cells, can stimulate $\mathrm{T}$ cell proliferation, and phagocytose microorganisms [27]. This premise strongly suggest that melanocytes have the capacity to inhibit proliferation of bacterial and fungal microorganisms, then the capacity to affect coronaviruses must be considered for more in-depth examination [33]. L dopa, another intermediate of melanogenesis, has the capacity to inhibit the production of proinflammatory cytokines by $\mathrm{T}$ lymphocytes and monocytes, thus down regulating immune and inflammatory responses [34].

It is possible that from an evolutionary point of view, the primary role of melanocytes is not to produce melanin, for melanin does not confer a selective advantage to the organisms, but that melanin production is only a secondary specialization so melanocytes must have other more important functions to perform [35]. Melanocytes in skin, and perhaps in oral mucosa express genes encoding corticotropin releasing factor (CRF), proopiomelanocortin (POMC), ACTH, Beta endorphins, Alpha-MSH and melanocortin-1 receptor (MC1R). These elements of the skin melanocortin system have the capacity to neutralize external noxious agents, to mediate local antimicrobial and immune responses, and to mediate local nociception $[36,37]$. UV radiation induces the generation of CRF, POMC and Alpha-MSH by cutaneous keratinocytes and melanocytes, bringing about an increase in melanin 
biosynthesis [38], imparting protection against solar radiation [35]. Similarly, with specific regard to the benefits of darkly pigmented people interdependence on regular exposure to sunlight in open environments fortifying healthy immune responses, there appears to be a direct link to the body's ability to maintain optimal levels of vitamin-D. This has been corroborated by [39], which strongly supports a definitive relationship to the administration of high doses of Calcifediol or 25-hydroxyvitamin D, a main metabolite of vitamin-D to significantly reduce the need for ICU treatment of patients diagnosed with COVID-19. Therefore, it is not biologically advantageous to be socially isolated indoors and away from the sun, which has consistently been linked to vitamin-D deficiencies [40]. Confirmation of treatment benefits among hospitalized COVID-19 patients continues to show promise with such supplemental interventions.

\section{Conclusion}

The way SARS-CoV-2 has impacted the world is devastating. Focusing on self-discipline and proper nourishment are needed to effectively combat this deadly coronavirus. A pigment powered defense system seems to be critical to survival and diminished morbidity [3]. Conversely, it also merits acknowledgment that melanin could possibly mask a double edge sword effect for melanin dominant individuals, due to being sequestered in their homes with diminished mobility and minimal exposure to sunlight makes it too difficult for their bodies to produce optimal levels derived from the lack of skin exposure to trigger vitamin-D synthesis. Although its presence is for protection, melanin can accumulate toxic elements and prompt an immune response that creates a cytotoxic environment.

Searching for a vaccine as a preventative panacea may not be the most expedient solution for this rare pandemic, given its ability to mutate strains faster than scientist's abilities to keep up. Serious emphasis should be placed on life supporting foods containing pigments and natural products that can enhance the defense mechanisms that synergistically regulate the endocrine system to awaken specific cellular armies in the immune system. For example, chlorophylls, carotenoids, and anthocyanins all have some degree of anti-inflammatory effects in humans, particularly the betacyanin in beets. As mentioned before throughout this narrative the media's focus on a vaccine has greatly limited the scope of finding accessible treatments to battle this one of many more viruses to come. In fact, there are more viruses on the planet than there are stars in the sky. Though, to acknowledge this reality can easily be reduced to academic discourse, the facts loom on the horizon, the lay public are compelled, and paralyzed awaiting touted to be highly effective vaccines with a plethora of unmentioned deleterious side effects. Most of which are occurring on the muted pages of statistically rare adverse contraindications while financial solvency of colossal corporate pharmaceutical entities monetary reserves increases exponentially, while people struggle to discern potential options to develop a biopsychosocial model to improve and maintain health. Research has shown that there are many effective therapeutic approaches that can be complementary to traditional "Western Medicine", however, as consumers of healthcare - traditional recipients of the medical model accepted interventions continue to ration or triage delivery of treatment to contain devastating health maladies. Invariably, this dampens the spirit and vigilance to pursue knowledge to empower people to take control of their health, there by, fostering a learned helplessness, and the cognitive default to their historical position of accepting the label of "patient" and simultaneously wait for epidemiologists and doctors to debate about the efficacy and access to needed health interventions.

In efforts to amplify the benefits of a basic sense of autonomy and fortifying one's immune system, natural elements like zinc are relegated as an anecdotal mentionables.
While the average Internist or nutritionist knows that a zinc deficiency can result from medications like ACE2 inhibitors and prolonged poor dietary practices. People on high blood pressure medicines like ACE2 inhibitors may be more susceptible to entry of SARS-CoV-2 into cells. And, referring to zinc, it is interesting that we need zinc for a proper sense of taste and smell, which has become part of the cluster of symptoms linked to a number COVID-19 patients losing those senses. It is note worthy that the nose is a major entry point for the virus to travel along the mucosa to tunnel access to olfactory cells because they have alarge number of ACE2 receptors on their surface [20]. Further, aldosterone and angiotensin II together change the properties of taste receptors in the tongue and neurons in the brain linked to taste in humans [41]. Simply put, studying the factors that make us vulnerable to coronaviruses should be highlighted, particularly those that are inherent in one's external environment milieu, which can become a fusion of diffuse stressors and of course any prescribed medications that may alter a person's microbiome, to the degree that they may have nondescript intermittent malaise, headaches, and gastrointestinal distress [42]. Combined, all of which could sound an alarm to overly engage one's immune system and trigger a random cytokine storm.

Drugs related to interferon and interleukin seem to be reasonably effective. However, the politics of vaccine production and capitalism present marginal interest in maintaining health $[5,43]$. The objective becomes - making stock holders purchase more shares, usually at the expense of good health. A health industry wedded to profit margins incentive is to make more money, which typically suggest, illness is highly correlated with quarterly revenues. Countries that are more socialistic have a better response to COVID-19. Cuba, for example, has been at the forefront of interferon research, however, the US embargo and the petty world politics manage to ignore effective treatments like Interferon-alpha26b from other countries [7].

Interferons seem to prevent cytokine storms. Take Bats for example, they carry many forms of coronaviruses without succumbing to the deadly disease, because bat's produce unusual amounts of antiviral cytokines like interferons. As reported by Velasquez-Manoff [7], mice studies have shown that mice infected with SARS-CoV-2 survived the infection if they quickly generated a strong interferon response. Animals that failed to produce interferon early, however, died not because the virus killed them but because they produce so much interferon later that their over reactive immune systems fostered their systems to shut down.

Even in studies with children, whose immune systems are immature and developing, there appears to be naturally high levels of interferons and other cytokines circulating in their bodies. It has been demonstrated that children also have high levels of an antiinflammatory cytokine called interleukin-10. This compound may play a role in preventing damage from the constant inflammation. The elevated baseline level of interferon and interleukin-10 maybe what helps children survive COVID-19. These levels decrease in adulthood, and adults can have a more difficult time to mount an interferon response. This deficiency may be related to older people's propensity to become more vulnerable to the disease progression from COVID-19.

Companies are creating inhalable interferon beta instead of the injectable form that has more side effects. In China and Cuba, antiviral medication plus an inhaled interferon called IFN-alpha2b has improved outcomes in a subset of patients. In summary, interferon may help to pre-empt an excessive immune response by helping to bring a virus under control at the start of an infection, there by diminishing a person's viral load, so there is no reason to over react later. Alternative treatments for COVID-19 are found in Table 4. 


\begin{tabular}{|ll|}
\hline - & Tocilizumab - blocks cytokine interleukin-6 (long-acting) \\
\hline$\cdot$ & Anakinra - blocks cytokine interleukin-1 (short-acting) \\
\hline$\cdot$ & Dexamethasone - steroidal immunosuppressant \\
\hline- & Interferon-Beta - immunomodulator \\
\hline- & Interferon-Alpha2b - immunomodulator \\
\hline- & Interferon-Gamma - immunomodulator \\
\hline Leronlimab - anti-inflammatory \\
\hline- & Colchicine - anti-inflammatory \\
\hline $\begin{array}{l}\text { Combination therapy is needed to combat cytokine storms. The above list are potential } \\
\text { agents that have been used in experiments to treat COVID-19 patients. }\end{array}$ \\
\hline
\end{tabular}

COVID-19 has altered every aspect of life on the planet, and melanin dominant people in a variety of urban and technologically advanced environments are disproportionately succumbing to this plague. This article was written with several objectives in mind, to draw attention to the role of (environmental factors), resource awareness, vaccine alternatives, and public health decisions to curtail viral threats. It is evident, that the medical-pharmaceutical-industrial complex have limited the choices available to people to choose between governmental guidance or (informed-knowledge) self-reliance, therefore consultation with your health care provider if you are on prescribed medications is advised. Know your body and how it feels when you are on medication, because every medication is not made to assist melanin-dominant biological systems. Be aware of what may be detrimental or beneficial because synthetic medicines like many blood pressure medicines may have cumulative contraindications - deleterious side-effects. Table 5 demonstrates natural products that enhances the lymphatic system's responsivity [Insert Table 5 here].

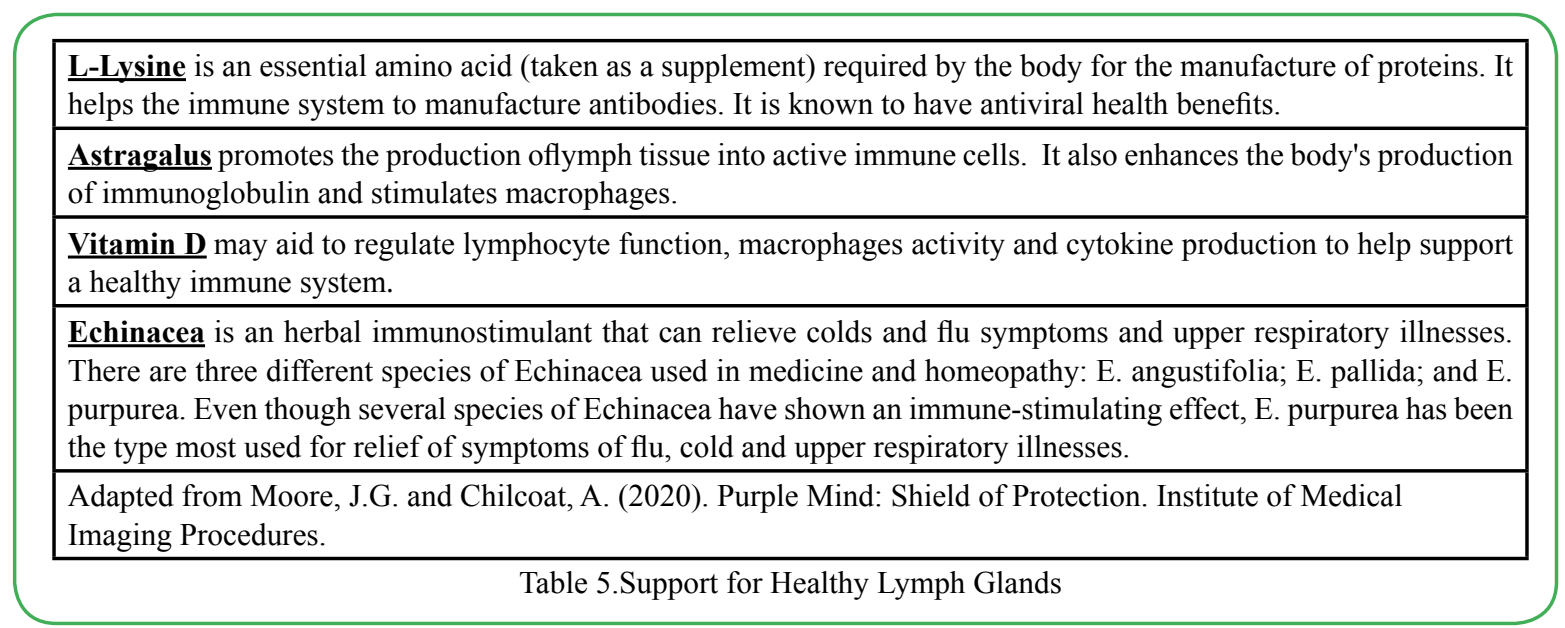

There are alternative approaches to treatment, so do not become dependent on the wishful desire to have a vaccine to rid us of this pandemic, which in time may be summarily mentioned as endemic. The advantages of melanin's capabilities to fight disease and boost our defense mechanisms are critical as we see the climate change. The natural immunomodulators like interferon and interleukin should be harnessed, and we must support the use of alternative therapies with compounds that can activate proper immune reactions. Since interferons are effective, and biological substances like MSH can be effective as antipyretic agents, we need to look at these as options to fight disease. In fact, the skin and cells in the lymphatic system can produce some of the same chemicals in the brain. More research on these cytokines produced in cells requires further study for humans to fight the continual onslaught of new viral threats lurking in our constantly degrading biosphere.

The ancient axiom of 'Know Thyself' is a fitting ending, because as humans become more disconnected from the earth and the oceans, the more likely we are to have viruses and new bacteria to thrive and reclaim ecosystems that allowed them to flourish millennia before humans walked on this planet. In closing, the earth is more than capable of regulating resource allocation if man would cease type casting himself as the decisive "Father-Mother God" of who lives and thrives. This remark begs the question of the level of global J Ment Health Soc Behav

Volume 3. 2021. 133 decimation and who are those people being disproportionately counted among the casualties. And equally important, subsequent sequelae scientists will euphemistically phase into the medical literature of some of the unforeseen health maladies destined to present among the people of color who survive the pandemic. In simple terms. Western Medicine is still a budding prepubescent child in the wilderness as she learns the power of complementary medicine, particularly in her commitment to heal or help Brown and Black people on the planet.

Conflict of Interest: Author declares no conflit of interest.

\section{References}

1. Paxman, R. and Harris, J. (1982). A Higher Form of Killing. Noonday Press: New York, NY.

2. Centers for Disease Control and Prevention. (2020, April). COVIDView: A weekly surveillance summary of U.S. COVID-19 activity. https://www.cdc.gov/coronavirus/2019-ncov/coviddata/covidview/index.html\#mortality

3. Moore, T.O. (2020). Pigment Power: Topics on Melanin in Science and Health. Zamani Press.

4. Pall, M.L. (2018). Wi-Fi is an important threat to human health. Environmental Research, Jul. 164, 405-416

5. Marrs, J. (2015). Population Control. Morrow: New York, NY. JMHSB, an open access journal 
6. Walter, M.R. (1997). Structural biology of cytokines, their receptors, and signaling complexes: Implications for the immune and neuroendocrine circuit. In J.E. Blalock (Ed.), Neuroimmonoendocrinology (3rd Rev. Ed.). Chemical Immunology, Vol. 69 (pp. 76-98). Karger.

7. Velasquez-Manoff, M. (2020). How covid sends some bodies to war with themselves. The New York Times, August 16. https:// www.nytimes.com/2020/08/11/magazine/covid-cytokinestorms.html

8. Villarreal, L.P. (2008). Are viruses alive? Scientific American. https://www.scientificamerican.com/article/are-virusesalive-2004/

9. Oxford, J., Kellam, P. and Collier, L. (2016) Human Virology 5th Edition, Oxford University Press

10. Anderson, K.G., Rambaut, A., Lipkin, W.I., Holmes, E.C. and Garry, R.F. (2020). The proximal origin of SARS-CoV-2. Nature Medicine. https://www.nature.com/articles/s41591-020-0820-9

11. Jones, J. (1981). Bad Blood: The Tuskegee Syphilis Experiment. The Free Press.

12. Washington, H.A. (2006). Medical Apartheid: The dark history of medical experimentation on Black Americans from colonial times to the present. Doubleday.

13. Carr, F.W. (2003). Germany's Black Holocaust 1890-1945. Scholar Technological Institute of Research (www.stirinc.org)

14. Banks, N.T. (2010). AIDS, Opium, Diamonds and Empire: The Deadly Virus of International Greed. iUniverse, Inc: Bloomington, IN.

15. Carter, C. (2020, September). How to stay healthy this winter. AARP Bulletin,(pp. 12-16).

16. Pearsall, P. (1987). Superimmunity: Master your emotions and improve your health. McGraw Hill Book Company.

17. Moore, J.G. and Chilcoat, A. (2020). Purple Mind: Shield of Protection. Institute of Medical Imaging Procedures.

18. Moore, T.O. Moore (2004). The Science of Melanin: The Second Edition. Zamani Press.

19. Mackintosh, J.A. (2001). The antimicrobial properties of melanocytes, melanosomes and melanin and the evolution ofblack skin. Journal of Theoretical Biology, July 21, 211(2), 101-113.

20. Cohn, M. (2020). Cover your nose: John Hopkins research suggests that's how coronavirus gains foothold. Baltimore Sun, August 21, https://news.yahoo.com/research-suggestscoronavirus-gains-foothold-211900497.html

21. Grollman, S. (1974). The Human Body: Its Structure and Physiology (3rd Ed.). Macmillan.

22. Kalat, J. (2019). Biological Psychology. (pp.300). Cengage.

23. Tanaka, J., Hayashi, Y., Nomura, S., Miyakubo, H., Okumura, T. \& Samaki, K. (2001). Angiotensinergic and noradrenergic mechanisms in the hypothalamic paraventricular nucleus participate in the drinking response induced by activation of the rat subfornicalorganinrats. BehavioralBrainResearch, 118, 117-122.

24. Anthony, C.P. and Kolthoff, N.J. (1975). The Textbook of Anatomy and Physiology (9th Ed.). p.284. The C.V. Mosby Company.

25. Jessop, D.S. (2002). Neuropeptides in the immune system: Functional roles in health and disease.In A.B. Grossman (Ed.), Neuroendocrine-Immune Interactions. Frontiers of Hormone Research,Vol 29 (pp. 50-68). Karger.

26. Wood, J.M., Jimbow, K., Boissy, R.E., Slominski, A., Plonka, P.M., Slawinski, J., Wortsman J.,\& Tosk, J.(1999). What's the use of generating melanin? Experimental Dermatology, 8, 153164. 10.1111/j.1600-0625.1999.tb00365.x.
27. Feller, L. Masilana, A., Khammissa, R.A.G., Altini, M., Jadwat, Y. \& Lemmer, J. (2014). Melanin: the biophysiology of oral melanocytes and physiological oral pigmentation. Head and Face Medicine, 10(8), https://head-face-med.biomedcentral. com/articles/10.1186/1746-160X-10-8

28. Bahloul, E., Jallouli, M., Garbaa, S., Marzouk, S., Masmoudi, A., Turk, H. \& Bahloul. (2017). Hydroxychloroquine-induced hyperpigmentation systemic diseases: prevalence, clinical features, and risk factors. Lupus, Oct, 26(12). https://pubmed. ncbi.nlm.nih.gov/28355984/

29. Jallouli, M., Francès, C., Piette, J.C., Huong du, L.T., Moguelet, P., Factor, C., Zahr, N., Miyara, M., Saadoun, D., Mathian, A., Haroche, J., De Gennes, C., Leroux, G., Chapelon, C., Wechsler, B., Cacoub, P., Amoura, Z., \&Costedoat-Chalumeau, N. (2013).Hydroxychloroquine-induced pigmentation in patients with systemic lupus erythematosus: a case-control study. JAMA Dermatology, Aug;149(8):935-40. doi: 10.1001/ jamadermatol.2013.709.PMID: 23824340

30. Vigneri, S. (2020,August/September). The vitamin D conundrum. AARP The Magazine, (pp. 18-19).

31. Cassell, D. K. (2020, October) New Study Found $80 \%$ of COVID-19 Patients Were Vitamin D Deficient.https://www. healthline.com/health-news/new-study-found-80-percent-ofcovid-19-patients-were-vitamin-d-deficient

32. McCrave, C. (2020). New research suggests vitamin D can reduce the severity of Covid-19 symptoms. The Journal.ie. https://www.thejournal.ie/vitamin-d-covid-19-trinity-collegeresearch-5082423-Apr2020/

33. Plonka, P.M. \& Grabacka, M. (2006). Melanin synthesis in microorganisms-biotechnological and medical aspects. Acta Biochim Pol., 53: 429-443.

34. Slominski, A., Zbytek, B., Slominski, R. (2009). Inhibitors of melanogenesis increase toxicity of cyclophosphamide and lymphocytes against melanoma cells. International Journal of Cancer Supplement, 124: 1470-1477. 10.1002/ijc.24005.

35. Plonka, P.M., Passeron, T., Brenner, M., Tobin, D.J., Shibahara, S., Thomas, A., Slominski, A., Kadekaro, A.L., Hershkovitz, D., Peters, E., Nordlund, J.J., Abdel-Malek, Z., Takeda, K., Paus, R., Ortonne, J.P., Hearing, V.J., \&Schallreuter, K.U. (2009). What are melanocytes really doing all day long...? Experimental Dermatology, 18: 799-819. 10.1111/j.1600-0625.2009.00912.x.

36. Slominski, A., Wortsman, J., Paus, R., Elias, P.M., Tobin, D.J., Feingold, K.R. (2008). Skin as an endocrine organ: implications for its function. Drug Discovery Today,5: 137-144. 10.1016/j. ddmec.2008.04.004.

37. Peters, A. (2005). The self-similarity of the melanocortin system. Endocrinology, 146: 529-531. 10.1210/en.2004-1475.

38. Millington, G.W. (2006). Proopiomelanocortin (POMC): the cutaneous roles of its melanocortin products and receptors. Clinical and Experimental Dermatology,31: 407-412. 10.1111/j.1365-2230.2006.02128.x.

39. Castillo, Marta Entrenas, et al. "Effect of Calcifediol Treatment and best Available Therapy versus best Available Therapy on Intensive Care Unit Admission and Mortality Among Patients Hospitalized for COVID-19: A Pilot Randomized Clinical study." The Journal of Steroid Biochemistry and Molecular Biology (2020): 105751.

40. Holick, M.F. (2010)The Vitamin-D Solution, Hudson Street Press

41. Krause,E.G. and Sakal, R.R. (2007). Richter and sodium appetite. From adrenalectomy to molecular biology. Appetite, 49, 353-367.

42. Anderson, J.F., Cryan, and T. Dinan (2019) The Psychobiotic Revolution: Mood, Food, and the New Science of the Gut-Brain Connection, National Geographic Partners, Wash, DC

43. Washington, H.A. (2011). Deadly Monopolies. Anchor Books. 